\title{
CD44 is associated with tumor recurrence and is an independent poor prognostic factor for patients with localized clear cell renal cell carcinoma after nephrectomy
}

\author{
BYUNG-JOO JEONG ${ }^{1}$, ZHE LONG LIANG ${ }^{1}$, SONG MEI HUANG ${ }^{1}$, \\ JAE SUNG LIM ${ }^{3}$, JIN MAN KIM ${ }^{1}$ and HYO JIN LEE ${ }^{2}$ \\ ${ }^{1}$ Department of Pathology, Cancer Research Institute and Infection Signaling Network Research Center, \\ ${ }^{2}$ Department of Internal Medicine and Cancer Research Institute; ${ }^{3}$ Department of Urology, \\ Chungnam National University School of Medicine, Daejeon, Republic of Korea
}

Received December 27, 2011; Accepted January 30, 2012

DOI: $10.3892 /$ etm.2012.505

\begin{abstract}
CD44 has been implicated in tumor development and progression in several types of cancer. CD44 expression is altered in renal cell carcinoma (RCC) and has been suggested as a useful prognostic marker, but its prognostic role in RCC remains controversial. We investigated the expression of CD44 in a large homogeneous set of localized clear cell RCC to determine its potential prognostic value. We examined 110 patients with localized clear cell RCC who underwent nephrectomy. The clinicopathological data were obtained retrospectively and the expression level of CD44 was studied by immunohistochemistry. Correlations between CD44 expression and clinical parameters as well as survival were determined. The CD44-high expression group (HEG) was significantly associated with a higher nuclear grade $(\mathrm{P}=0.014)$ and tumor recurrence $(\mathrm{P}<0.001)$ when compared with the CD44-low expression group (LEG). Concerning survival, the 5-year recurrence-free survival (RFS) rates for the CD44-HEG and CD44-LEG groups were 38.9 and $91.3 \%$, respectively $(\mathrm{P}<0.001)$, and the 5-year disease-specific survival (DSS) rates for the CD44-HEG and CD44-LEG groups were 55.6 and $94.6 \%$, respectively $(\mathrm{P}<0.001)$. Multivariate analyses showed that CD44 expression [hazard ratio (HR), 9.204; $\mathrm{P}<0.001$ ] was an independent risk factor predicting RFS in patients with clear cell RCC. CD44 expression remained an independent prognostic factor for DSS ( $\mathrm{P}=0.002)$. In conclusion,
\end{abstract}

Correspondence to: Professor Jin Man Kim, Department of Pathology, Cancer Research Institute and Infection Signaling Network Research Center, Chungnam National Univerisity School of Medicine, Daejeon, Republic of Korea

E-mail:jinmank@cnu.ac.kr

Professor Hyo Jin Lee, Department of Internal Medicine and Cancer Research Institute, Chungnam National University School of Medicine, Daejeon, Republic of Korea

E-mail: cymed@cnu.ac.kr

Key words: renal cell carcinoma, CD44, prognosis, survival these data indicate that CD44 expression is associated with the progression of clear cell RCC and is an independent poor prognostic factor for tumor recurrence and survival, suggesting that CD44 may serve as a useful molecular marker.

\section{Introduction}

Renal cell carcinoma (RCC) is one of the most lethal urologic cancers, with a global incidence of approximately 200,000 new cases and a mortality rate of more than 100,000 patients annually (1). Of all patients with RCC, 20-30\% subsequently experience local or distant recurrence within 5 years after an initial curative nephrectomy $(2,3)$. RCC has a dismal prognosis after metastasis has occurred, although immunotherapy and several molecular-targeted agents lead to prolonged survival in some patients with 5 -year survivals of $<20 \%(4,5)$. Therefore, it is important to predict which patients will develop disease recurrence after surgery for localized RCC.

Currently, several prognostic models for non-metastatic RCC, such as the University of California Los Angeles Integrated Staging System and the stage, size, grade and necrosis score, are mainly based on clinicopathological parameters (6-8). The most important conventional features are pathological tumor-node-metastasis stage, Fuhrman nuclear grade and Eastern Cooperative Oncology Group performance status (ECOG PS). Although risk grouping with these features is possible, significant heterogeneity persists among patients with a similarly predicted prognosis. In addition to clinicopathological prognostic features, several molecular and genetic tissue markers have been investigated as potential prognosticators for RCC, suggesting that molecular markers may play an important role in predicting prognosis $(4,9,10)$.

CD44 is a ubiquitous multistructural and multifunctional cell surface adhesion molecule involved in cell-cell and cell-matrix interactions. Several isoforms of CD44 have been identified and are the result of alternative post-transcriptional splicing modifications of 10 exons within a single gene located on the short arm of chromosome 11. CD44 transmembrane glycoproteins were originally described to mediate lymphocyte homing to peripheral lymphoid tissues through an interaction 
with hyaluronic acid on high endothelial venules (11-13). The standard form of CD44 is the main receptor for hyaluronate and has been found to play a vital role in the hematogenous dissemination of tumor cells in various human cancers (14). Although CD44 is closely associated with proliferation, metastasis, cancer recurrence and prognosis, contradictory results have been reported concerning CD44 overexpression in relation to tumor development and progression in different tumors at different sites (15). CD44 expression is altered in RCC and has been suggested as a useful prognostic marker, but its prognostic role in RCC remains controversial $(13,16-23)$. In the present study, we examined CD44 expression as a prognostic marker in tumor specimens from patients with localized clear cell RCC (CCRCC) and investigated the relationship between CD44 expression and clinicopathological features and patient survival.

\section{Materials and methods}

Patients and tumor samples. We retrospectively investigated 110 consecutive patients with CCRCC who underwent a radical or partial nephrectomy for sporadic, localized RCC (pT1-3N0M0) at the Chungnam National University Hospital, Daejeon, Korea, between 2000 and 2006. Clinicopathological baseline data were obtained through medical record review. ECOG performance status was assigned to each patient at the time of diagnosis. T classification was defined according to the 2002 American Joint Committee on Cancer criteria and nuclear grade was determined according to Fuhrman's grading system. Tumor samples were collected from tissue blocks used for routine pathological examination. This study was approved by the local ethics committee.

Tissue microarray construction. Tissue microarrays were constructed from 110 archival, original, formalin-fixed, paraffin-embedded tissue blocks of localized CCRCC. A representative tumor area was carefully selected from a hematoxylin and eosin-stained section of each donor block. Each case was represented by two cylindrical cores (2-mm diameter) from a tumor, which was punched using an automated tissue arrayer (UNITMA, Seoul, Korea). Thus, tissue microarray blocks containing 220 cylinders were constructed.

Specimen preparation and immunohistochemistry. Sections (3- $\mu \mathrm{m}$ thick) were cut from recipient blocks, placed on 3-amino-propyltriethoxysilane-coated slides and dried at $57^{\circ} \mathrm{C}$ for $2 \mathrm{~h}$ before staining. All procedures were performed at room temperature, as recommended by the manufacturer. Briefly, sections were dewaxed in xylene and rehydrated in a graded alcohol series. Sections were then washed in water before antigen retrieval using a Dako PTLink machine (Dako, Glostrup, Denmark) with $10 \mathrm{mM}$ sodium citrate buffer (pH 6.0) at $97^{\circ} \mathrm{C}$ for $20 \mathrm{~min}$. The sections were then treated with $3 \%$ hydrogen peroxide for $10 \mathrm{~min}$ to block endogenous peroxidase and were preincubated with a serum-free protein block solution (Dako, Carpinteria, CA, USA) for $20 \mathrm{~min}$ to eliminate background staining. Monoclonal mouse CD44 antibody (NeoMarkers, Fremont, CA, USA) as a primary antibody was diluted 1:800 with background-reducing diluents (Dako, Carpinteria, CA, USA). After $30 \mathrm{~min}$ of incubation
Table I. Patient characteristics.

\begin{tabular}{|c|c|c|c|}
\hline Features & $\mathrm{N}$ & & $(\%)$ \\
\hline \multicolumn{4}{|l|}{ Age, years } \\
\hline Median & \multicolumn{3}{|c|}{60} \\
\hline Range & \multicolumn{3}{|c|}{$30-78$} \\
\hline \multicolumn{4}{|l|}{ Gender } \\
\hline Male & 79 & & 71.8 \\
\hline Female & 31 & & 28.2 \\
\hline \multicolumn{4}{|l|}{ ECOG PS } \\
\hline 0 & 49 & & 44.5 \\
\hline$\geq 1$ & 61 & & 55.5 \\
\hline \multicolumn{4}{|c|}{ Tumor size, cm } \\
\hline Median & & 5 & \\
\hline Range & & $1-15$ & \\
\hline \multicolumn{4}{|l|}{ T stage } \\
\hline pT1a & 25 & & 22.7 \\
\hline pT1b & 22 & & 20.0 \\
\hline pT2 & 17 & & 15.5 \\
\hline pT3a & 39 & & 35.5 \\
\hline $\mathrm{pT} 3 \mathrm{~b}$ & 7 & & 6.4 \\
\hline \multicolumn{4}{|c|}{ Fuhrman nuclear grade } \\
\hline 1 & 16 & & 14.5 \\
\hline 2 & 75 & & 68.2 \\
\hline 3 & 16 & & 14.5 \\
\hline 4 & 3 & & 2.7 \\
\hline
\end{tabular}

ECOG, Eastern Cooperative Oncology Group; PS, performance status.

in a humidity chamber and a wash with Tris-buffered saline Tween-20 (TBS-T), the slides were incubated for $30 \mathrm{~min}$ with an EnVision anti-mouse (Dako, Glostrup, Denmark) polymer. Reaction products were visualized with diaminobenzidine plus substrate-chromogen solution applied for $5 \mathrm{~min}$. The slides were counterstained with Meyer's hematoxylin and mounted. Careful rinses with several changes of phosphate-buffered saline (PBS) were performed between each stage of the procedure. Negative controls were prepared by excluding the primary antibody.

Evaluation of immunohistochemical staining. The immunohistochemical staining results were evaluated by two independent pathologists (Jin Man Kim and Zhe Long Liang), who were blinded to the clinicopathological details of the patients. Immunohistochemical staining was categorized according to a scoring method; tumors were classified into four grades based on staining intensity ( 0 , none; 1 , weak; 2 , intermediate; and 3, strong). In the case of heterogeneous staining within a sample, the respective higher score was chosen if $>50 \%$ of cells exhibited that staining intensity. The scores of two tumor cores from each patient were averaged to obtain a mean score. Cases with staining intensity scores of 0-2 were placed in the CD44-low expression group (CD44-LEG), and 
those with staining intensity scores of 3 were placed in the CD44-high expression group (CD44-HEG).

Statistical analyses. Pearson's $\chi^{2}$ test was used to assess the correlation between CD44 expression and clinicopathological features. Recurrence-free survival (RFS), disease-specific survival (DSS) and overall survival (OS) were estimated using the Kaplan-Meier method and the log-rank test. RFS was measured from the date of nephrectomy to the date of recurrence or death from CCRCC. DSS was measured from the date of nephrectomy to the date of death from CCRCC only. OS was measured from the date of surgery to the date of death from all causes. A Cox's proportional hazards model was prepared to analyze the effect of CD44 expression on RFS, DSS and OS. A P-value $<0.05$ was considered statistically significant. All statistical analyses were conducted using SPSS statistical software (vers. 13.0; SPSS, Inc., Chicago, IL, USA).

\section{Results}

Patient characteristics. The patient characteristics are summarized in Table I. Median age was 60 years (range, $30-78$ years), and $71.8 \%$ of the patients were male. Of the patients, $44.5 \%$ were ECOG 0, whereas 53.6 and $1.8 \%$ were ECOG 1 and 2, respectively. Median tumor size was $5 \mathrm{~cm}$ (range, $1-15 \mathrm{~cm}$ ). Of the patients, $42.7,15.5$ and $41.9 \%$ had pT1-pT3 primary tumors, respectively. Fuhrman nuclear grading demonstrated grade 1-4 lesions in $14.5,68.2,14.5$ and $2.7 \%$ of patients, respectively. In total, $17.3 \%$ of the patients experienced recurrence following nephrectomy (Table II).

Immunohistochemical analysis for CD44 expression in $C C R C C$. We analyzed the expression patterns of the CD44 protein using immunohistochemistry from the tissue microarrays (TMAs) of 110 patients with CCRCC. CD44 was diversely stained mainly in the membrane and cytoplasm of CCRCC cells (Fig. 1). Next, we assessed CD44 expression levels by determining the positively stained tumor cells using the staining intensity score $(0,+1,+2$ and +3$)$. Eighteen cases $(16.4 \%)$ showed +3 staining intensity (CD44-HEG), whereas 92 cases $(83.6 \%)$ showed +2 (21 cases), +1 (16 cases) or 0 (55 cases) staining intensity (CD44-LEG).

Correlation between CD44 expression and clinicopathological features. We next investigated the correlation between CD44 expression and various clinicopathological parameters. The results are summarized in Table II. No significant difference in age, gender, ECOG PS or tumor size was detected. However, CD44-HEG tumors tended to have a higher T stage (pT2 and pT3) compared with CD44-LEG tumors (72.2 vs. 53.3\%). Furthermore, the CD44-HEG group was significantly associated with a higher nuclear grade $(\mathrm{P}=0.014)$ and tumor recurrence $(\mathrm{P}<0.001)$ than those in the CD44-LEG group.

Correlation between CD44 expression and survival. To further investigate the clinical usefulness of CD44 expression in CCRCC, we compared RFS, DSS and OS based on CD44 expression. The 5-year RFS, DSS and OS rates were 82.7, 88.2 and $81.8 \%$, respectively, for the entire study population. The
Table II. Associations of the expression of CD44 with clinicopathological parameters.

\begin{tabular}{|c|c|c|c|c|c|}
\hline \multirow[b]{3}{*}{ Features } & \multicolumn{4}{|c|}{ CD44 expression } & \multirow[b]{3}{*}{ P-value } \\
\hline & \multicolumn{2}{|c|}{ LEG $(n=92)$} & \multicolumn{2}{|c|}{ HEG $(n=18)$} & \\
\hline & $\mathrm{N}$ & $(\%)$ & $\mathrm{N}$ & $(\%)$ & \\
\hline \multicolumn{6}{|l|}{ Age, years } \\
\hline$\leq 70$ & 79 & 85.9 & 12 & 82.7 & 0.81 \\
\hline$>70$ & 13 & 14.1 & 6 & 17.3 & \\
\hline \multicolumn{6}{|l|}{ Gender } \\
\hline Male & 64 & 69.6 & 15 & 83.3 & 0.390 \\
\hline Female & 28 & 30.4 & 3 & 16.7 & \\
\hline \multicolumn{6}{|l|}{ ECOG PS } \\
\hline 0 & 38 & 41.3 & 11 & 61.1 & 0.194 \\
\hline$\geq 1$ & 54 & 58.7 & 7 & 38.9 & \\
\hline \multicolumn{6}{|c|}{ Tumor size, $\mathrm{cm}$} \\
\hline$\leq 10$ & 87 & 94.6 & 16 & 88.9 & 0.321 \\
\hline$>10$ & 5 & 5.4 & 2 & 11.1 & \\
\hline \multicolumn{6}{|l|}{ T stage } \\
\hline $\mathrm{T} 1$ & 43 & 46.7 & 5 & 27.8 & 0.195 \\
\hline $\mathrm{T} 2 / 3$ & 49 & 53.3 & 13 & 72.2 & \\
\hline \multicolumn{6}{|c|}{$\begin{array}{l}\text { Fuhrman nuclear } \\
\text { grade }\end{array}$} \\
\hline G1 & 15 & 16.3 & 1 & 5.6 & 0.014 \\
\hline $\mathrm{G} 2$ & 65 & 70.7 & 10 & 55.6 & \\
\hline G3 & 10 & 10.9 & 6 & 33.3 & \\
\hline G4 & 2 & 2.2 & 1 & 5.6 & \\
\hline \multicolumn{6}{|l|}{ Recurrence } \\
\hline No & 84 & 91.3 & 7 & 38.9 & $<0.001$ \\
\hline Yes & 8 & 8.7 & 11 & 61.1 & \\
\hline
\end{tabular}

LEG, low-expression group; HEG, high-expression group. ECOG, Eastern Cooperative Oncology Group; PS, performance status.

survival curves according to CD44 expression are depicted in Fig. 2. The 5-year RFS rates for the CD44-HEG and CD44-LEG groups were 38.9 and $91.3 \%$, respectively (Fig. 2A; $\mathrm{P}<0.001$ ), and the 5-year DSS rates for the CD44-HEG and CD44-LEG groups were 55.6 and 94.6\%, respectively (Fig. 2B; $\mathrm{P}<0.001$ ). The rates of 5 -year OS were 50.0 and $88.0 \%$, respectively (Fig. 2C; $\mathrm{P}<0.001$ ). These results clearly show the significant effect of CD44 expression on clinical outcome in patients with localized CCRCC.

Univariate analyses were performed to assess the clinical significance of various parameters that might influence tumor recurrence and survival in patients with CCRCC. As summarized in Table III, Fuhrman nuclear grade $(\mathrm{P}=0.010)$ and CD44 expression $(\mathrm{P}<0.001)$ were significant risk factors affecting the RFS of patients with CCRCC. Age $(\mathrm{P}=0.026)$, Fuhrman nuclear grade $(\mathrm{P}=0.006)$ and $\mathrm{CD} 44$ expression $(\mathrm{P}<0.001)$ were also significant risk factors for DSS. Furthermore, age $(\mathrm{P}=0.021)$, Fuhrman nuclear grade $(\mathrm{P}=0.028)$ and $\mathrm{CD} 44$ 


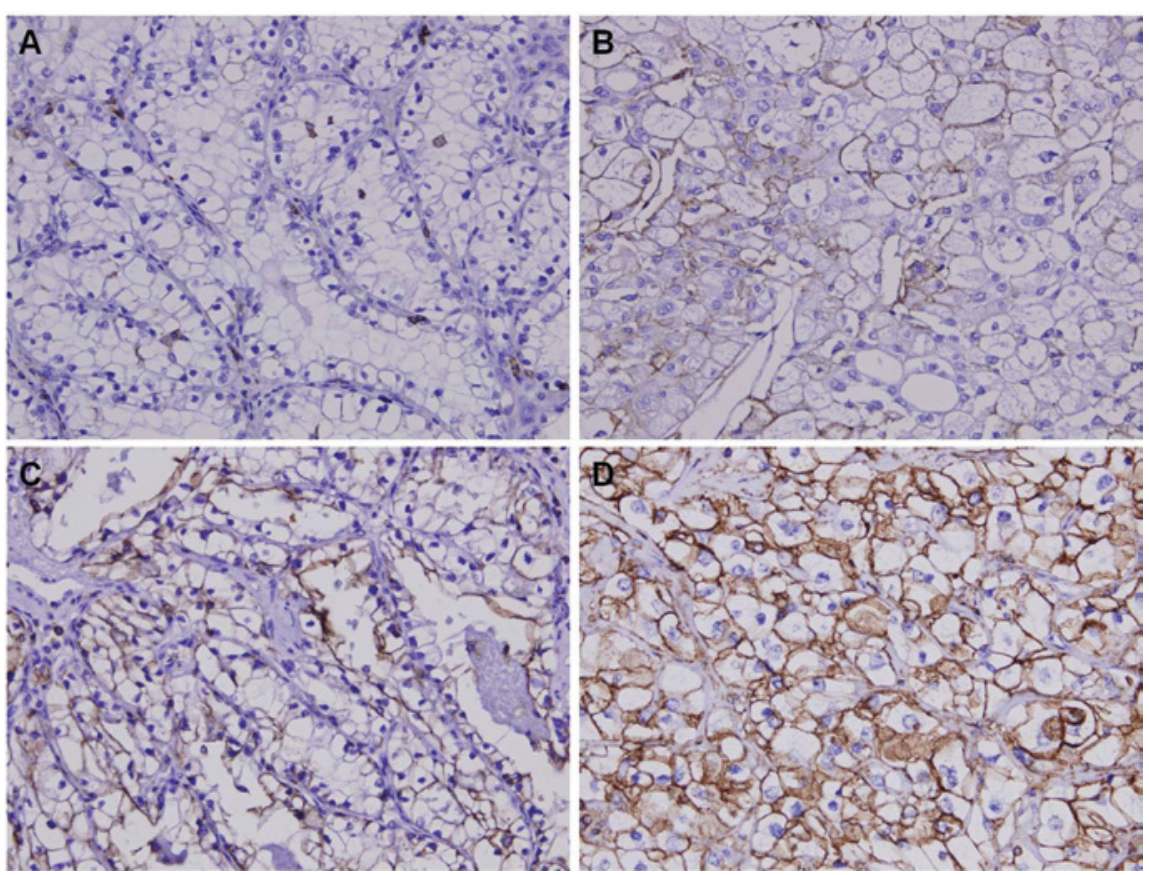

Figure 1. Representative photomicrographs of immunohistochemical staining for CD44 in renal cell carcinoma tissues. No staining intensity (A), weak staining intensity (B), intermediate staining intensity (C) and strong staining intensity (D) (magnification, $\mathrm{x} 400$ ).

Table III. Univariate analyses of the association of prognosis with clinicopathological parameters and CD44 expression in patients with renal cell carcinoma.

\begin{tabular}{|c|c|c|c|}
\hline Variables & HR & $95 \% \mathrm{CI}$ & P-value \\
\hline \multicolumn{4}{|l|}{ Recurrence-free survival } \\
\hline Age (>70/ $\leq 70$ years $)$ & 1.908 & $0.686-5.302$ & 0.215 \\
\hline Gender (male/female) & 2.333 & $0.680-8.009$ & 0.178 \\
\hline ECOG PS $(\geq 1 / 0)$ & 0.873 & $0.355-2.149$ & 0.768 \\
\hline Tumor size $(>10 / \leq 10 \mathrm{~cm})$ & 3.405 & $0.990-11.714$ & 0.052 \\
\hline Pathologic T stage (T2-3/T1) & 2.430 & $0.875-6.750$ & 0.088 \\
\hline Fuhrman nuclear grade (G3-4/G1-2) & 3.433 & $1.350-8.727$ & 0.010 \\
\hline CD44 expression (high/low) & 9.669 & $3.869-24.162$ & $<0.001$ \\
\hline \multicolumn{4}{|l|}{ Disease-specific survival } \\
\hline Age $(>70 / \leq 70$ years $)$ & 3.571 & $1.165-10.947$ & 0.026 \\
\hline Gender (male/female) & 4.928 & $0.641-37.908$ & 0.125 \\
\hline ECOG PS $(\geq 1 / 0)$ & 0.911 & $0.306-2.710$ & 0.867 \\
\hline Tumor size $(>10 / \leq 10 \mathrm{~cm})$ & 2.995 & $0.663-13.520$ & 0.154 \\
\hline Pathologic T stage (T2-3/T1) & 2.855 & $0.785-10.377$ & 0.111 \\
\hline Fuhrman nuclear grade (G3-4/G1-2) & 4.683 & $1.572-13.954$ & 0.006 \\
\hline CD44 expression (high/low) & 10.421 & $3.393-32.002$ & $<0.001$ \\
\hline \multicolumn{4}{|l|}{ Overall survival } \\
\hline Age (>70/ $\leq 70$ years $)$ & 2.925 & $1.178-7.265$ & 0.021 \\
\hline Gender (male/female) & 1.328 & $0.487-3.627$ & 0.579 \\
\hline ECOG PS $(\geq 1 / 0)$ & 0.855 & $0.363-2.012$ & 0.719 \\
\hline Tumor size $(>10 / \leq 10 \mathrm{~cm})$ & 1.754 & $0.408-7.535$ & 0.450 \\
\hline Pathologic T stage (T2-3/T1) & 1.720 & $0.694-4.262$ & 0.242 \\
\hline Fuhrman nuclear grade (G3-4/G1-2) & 2.767 & $1.115-6.863$ & 0.028 \\
\hline CD44 expression (high/low) & 5.509 & $2.274-13.348$ & $<0.001$ \\
\hline
\end{tabular}

HR, hazard ratio; CI, confidence interval. ECOG, Eastern Cooperative Oncology Group; PS, performance status. 

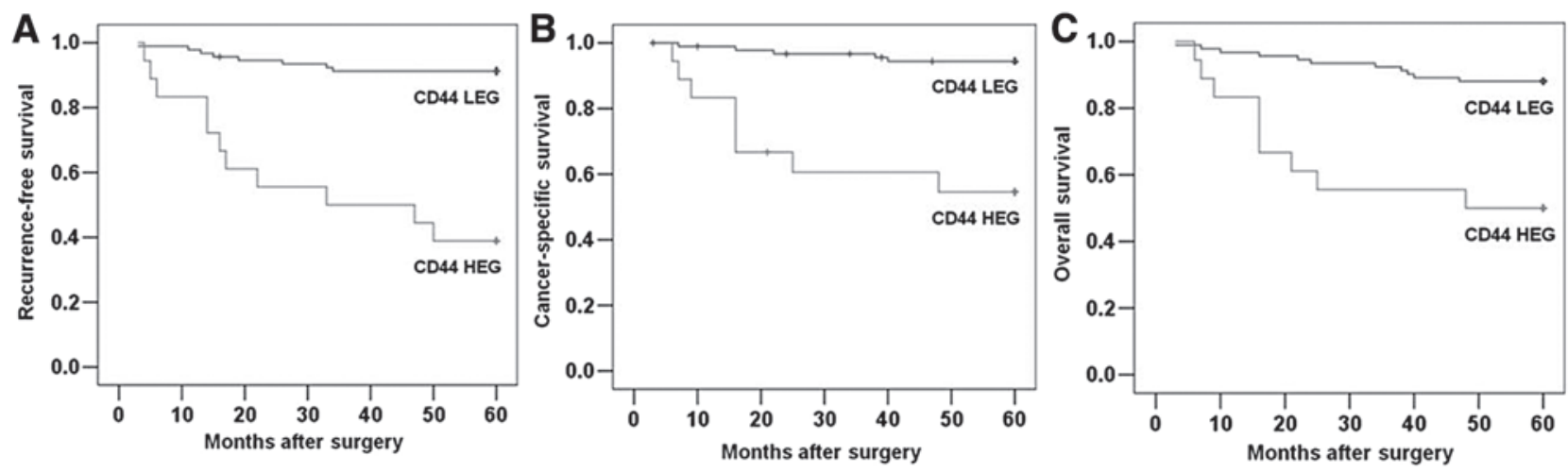

Figure 2. Correlation between CD44 expression and survival rates in patients with clear cell renal cell carcinoma. Five-year recurrence-free survival $(\mathrm{P}<0.001)(\mathrm{A})$; 5-year disease-specific survival $(\mathrm{P}<0.001)(\mathrm{B})$; and 5-year overall survival $(\mathrm{P}<0.001)(\mathrm{C})$.

Table IV. Multivariate analyses of the association of prognosis with clinicopathological parameters and CD44 expression in patients with renal cell carcinoma.

\begin{tabular}{|c|c|c|c|}
\hline Variables & HR & $95 \% \mathrm{CI}$ & P-value \\
\hline \multicolumn{4}{|l|}{ Recurrence-free survival } \\
\hline Age (>70/s70 years) & 0.909 & $0.293-2.819$ & 0.869 \\
\hline Gender (male/female) & 2.057 & $0.523-8.088$ & 0.302 \\
\hline ECOG PS $(\geq 1 / 0)$ & 1.657 & $0.593-4.635$ & 0.336 \\
\hline Tumor size $(>10 / \leq 10 \mathrm{~cm})$ & 3.150 & $0.729-13.613$ & 0.125 \\
\hline Pathologic T stage (T2-3/T1) & 1.786 & $0.604-5.276$ & 0.294 \\
\hline Fuhrman nuclear grade (G3-4/G1-2) & 1.212 & $0.410-3.580$ & 0.728 \\
\hline CD44 expression (high/low) & 9.204 & $3.196-26.506$ & $<0.001$ \\
\hline \multicolumn{4}{|l|}{ Disease-specific survival } \\
\hline Age (>70/ $\leq 70$ years $)$ & 1.976 & $0.519-7.526$ & 0.318 \\
\hline Gender (male/female) & 3.401 & $0.385-30.004$ & 0.271 \\
\hline ECOG PS $(\geq 1 / 0)$ & 2.089 & $0.567-7.699$ & 0.268 \\
\hline Tumor size $(>10 / \leq 10 \mathrm{~cm})$ & 1.901 & $0.313-11.552$ & 0.485 \\
\hline Pathologic T stage (T2-3/T1) & 2.098 & $0.533-8.256$ & 0.289 \\
\hline Fuhrman nuclear grade (G3-4/G1-2) & 1.955 & $0.535-7.142$ & 0.311 \\
\hline CD44 expression (high/low) & 7.927 & $2.113-29.737$ & 0.002 \\
\hline \multicolumn{4}{|l|}{ Overall survival } \\
\hline Age (>70/ $\leq 70$ years $)$ & 2.641 & $0.938-7.436$ & 0.066 \\
\hline Gender (male/female) & 1.139 & $0.347-3.741$ & 0.830 \\
\hline ECOG PS $(\geq 1 / 0)$ & 1.347 & $0.499-3.636$ & 0.556 \\
\hline Tumor size $(>10 / \leq 10 \mathrm{~cm})$ & 1.029 & $0.203-5.210$ & 0.937 \\
\hline Pathologic T stage (T2-3/T1) & 1.280 & $0.488-3.355$ & 0.616 \\
\hline Fuhrman nuclear grade (G3-4/G1-2) & 2.216 & $0.739-6.113$ & 0.162 \\
\hline CD44 expression (high/low) & 4.001 & $1.440-11.116$ & 0.008 \\
\hline
\end{tabular}

HR, hazard ratio; CI, confidence interval. ECOG, Eastern Cooperative Oncology Group; PS, performance status.

expression $(\mathrm{P}<0.001)$ were significant risk factors for OS. Multivariate analyses were performed using Cox's proportional hazards model to determine the independent prognostic effects of these factors. These analyses showed that CD44 expression [hazard ratio (HR), 9.204; $95 \%$ confidence interval (CI), 3.196-26.506; $\mathrm{P}<0.001$ ] was an independent risk factor predicting RFS in patients with CCRCC (Table IV). CD44 expression remained an independent prognostic factor for DSS and OS ( $\mathrm{P}=0.002$ and 0.008 , respectively; Table IV). Taken together, our findings indicate that CD44 overexpression could be a useful marker to predict tumor recurrence and survival in patients with localized CCRCC. 


\section{Discussion}

To our knowledge, this is the largest study to identify CD44 expression as an independent poor prognostic marker for RFS, DSS and OS in patients who have undergone nephrectomy for localized CCRCC. Patients with high CD44 expression were at 9.2-, 7.9- and 4.0-fold increased risk for poor RFS, DSS and OS, respectively. These results may have important clinical implications for risk stratification, planning of meticulous postsurgical surveillance and the development of adjuvant clinical trials.

CD44 proteins have been implicated in several cellular functions, including cell-cell and cell-matrix adhesion, migration and tumor metastasis. Cell adhesion and migration are critical steps in malignancy, and hyaluronic acid, which is the main component of the extracellular matrix, can activate the CD44 receptor, resulting in adhesion, invasion, and extravasation for metastasis. CD44 also interacts with soluble extracellular proteins and acts as a platform to harbor growth factors and matrix metalloproteinases. The binding of heparinbinding growth factor to heparan sulfate proteoglycans is prerequisite to the activation of the high-affinity epidermal growth factor receptor 4 tyrosine kinase, which signals cell survival $(24,25)$. CD44 ablation in some types of murine and human cancers significantly reduces tumor induction (26-28) Antibody blockade of CD44 results in a significant reduction in the invasive capacity of tumor cells in patients with RCC (19). However, the mechanism of such pathogenesis has not been clearly elucidated.

Several CD44 isoforms are the products of alternative splicing, resulting in considerable heterogeneity in CD44 expression among different tissues (29). The clinical significance of CD44 and its variants in various cancers is the subject of ongoing debate, due to contradictory findings regarding its prognostic and predictive value $(15,29)$. The significance of CD44 isoforms in RCC progression and metastasis is also controversial, and most studies have examined small, heterogeneous cohorts of patients with varying demographic parameters, such as histology and tumor extent (13,16-19,21-23). Tawfik et al (13) and Lucin et al (20) reported that CD44 shows no independent prognostic value for the prediction of patient survival. Bamias et al (16) also indicated that CD44 expression tended to correlate with $\mathrm{T}$ stage, but found no association between CD44 expression and survival. Additionally, Matusan et al (23) reported that upregulation of the CD44s and v6 isoforms, although found in a considerable number of papillary RCCs, appears to have no prognostic value in this type of renal cancer. However, Paradis et al (18) demonstrated that CD44 is an independent prognostic factor for OS and DFS, suggesting that it could be a useful prognostic parameter in conventional RCC, although they analyzed only 66 cases. Gilcrease et al (21) also reported that CD44 expression correlated with progression or recurrence in only 25 patients with CCRCC. Rioux-Leclercq et al (19) showed that CD44 expression appeared to be a powerful marker for identifying patients with an adverse prognosis, although the study included 73 patients with differing histology and tumor extent. In the present study, we focused on patients with localized CCRCC who underwent curative surgery because this population was homogeneous. The ability to predict which patients will develop recurrence after surgery is valuable; the identification of a new molecular marker is thus greatly needed. Our results showed that CD44 expression tended to be correlated with $\mathrm{T}$ stage and was significantly associated with Fuhrman nuclear grade, comparable with other reports $(30,31)$. Furthermore, univariate and multivariate analyses showed that CD44 expression was significantly associated with RFS, DSS and OS, suggesting that it might be a useful prognostic marker independent of other factors.

Our study had some limitations. First, this study was based on a retrospective analysis, although all patients in our study population had CCRCC and were followed up for at least 5 years. Second, the number of patients was relatively small, although this study was the largest providing evidence that CD44 expression is inversely related to survival in patients with CCRCC who underwent curative surgery. Thus, a welldesigned prospective study with a large number of patients is needed.

In conclusion, our results indicate that CD44 expression was associated with the progression of CCRCC and was an independent poor prognostic factor for tumor recurrence and survival, suggesting that CD44 may serve as a useful molecular marker.

\section{Acknowledgements}

This research was supported by the National Research Foundation of Korea (NRF) grant funded by the Korea government (MEST) (no. 2011-0006229).

\section{References}

1. Parkin DM, Bray F, Ferlay J and Pisani P: Global cancer statistics, 2002. CA Cancer J Clin 55: 74-108, 2005.

2. Crispen PL, Boorjian SA, Lohse CM, Leibovich BC and Kwon ED: Predicting disease progression after nephrectomy for localized renal cell carcinoma: the utility of prognostic models and molecular biomarkers. Cancer 113: 450-460, 2008.

3. Zisman A, Pantuck AJ, Wieder J, et al: Risk group assessment and clinical outcome algorithm to predict the natural history of patients with surgically resected renal cell carcinoma. J Clin Oncol 20: 4559-4566, 2002.

4. Klatte T, Seligson DB, Leppert JT, et al: The chemokine receptor CXCR3 is an independent prognostic factor in patients with localized clear cell renal cell carcinoma. J Urol 179: 61-66, 2008.

5. Motzer RJ, Hutson TE, Tomczak P, et al: Overall survival and updated results for sunitinib compared with interferon alfa in patients with metastatic renal cell carcinoma. J Clin Oncol 27: 3584-3590, 2009.

6. Frank I, Blute ML, Cheville JC, Lohse CM, Weaver AL and Zincke H: An outcome prediction model for patients with clear cell renal cell carcinoma treated with radical nephrectomy based on tumor stage, size, grade and necrosis: the SSIGN score. J Urol 168: 2395-2400, 2002

7. Patard JJ, Kim HL, Lam JS, et al: Use of the University of California Los Angeles integrated staging system to predict survival in renal cell carcinoma: an international multicenter study. J Clin Oncol 22: 3316-3322, 2004.

8. Zisman A, Pantuck AJ, Dorey F, et al: Improved prognostication of renal cell carcinoma using an integrated staging system. J Clin Oncol 19: 1649-1657, 2001.

9. Lam JS, Klatte T, Kim HL, et al: Prognostic factors and selection for clinical studies of patients with kidney cancer. Crit Rev Oncol Hematol 65: 235-262, 2008.

10. Volpe A and Patard JJ: Prognostic factors in renal cell carcinoma. World J Urol 28: 319-327, 2010.

11. Marhaba R and Zoller M: CD44 in cancer progression: adhesion, migration and growth regulation. J Mol Histol 35: 211-231, 2004. 
12. Naor D, Sionov RV and Ish-Shalom D: CD44: structure, function, and association with the malignant process. Adv Cancer Res 71: 241-319, 1997.

13. Tawfik OW, Kramer B, Shideler B, Danley M, Kimler BF and Holzbeierlein J: Prognostic significance of CD44, platelet-derived growth factor receptor alpha, and cyclooxygenase 2 expression in renal cell carcinoma. Arch Pathol Lab Med 131: 261-267, 2007.

14. Liao HX, Lee DM, Levesque MC and Haynes BF: N-terminal and central regions of the human CD44 extracellular domain participate in cell surface hyaluronan binding. J Immunol 155: 3938-3945, 1995

15. Lim SD, Young AN, Paner GP and Amin MB: Prognostic role of CD44 cell adhesion molecule expression in primary and metastatic renal cell carcinoma: a clinicopathologic study of 125 cases. Virchows Arch 452: 49-55, 2008.

16. Bamias A, Chorti M, Deliveliotis C, et al: Prognostic significance of CA 125, CD44, and epithelial membrane antigen in renal cel carcinoma. Urology 62: 368-373, 2003.

17. Wu ST, Sun GH, Hsieh DS, Chen A, Chen HI, Chang SY and Yu D: Correlation of CD44v5 expression with invasiveness and prognosis in renal cell carcinoma. J Formos Med Assoc 102: 229-233, 2003.

18. Paradis V, Ferlicot S, Ghannam E, et al: CD44 is an independent prognostic factor in conventional renal cell carcinomas. J Urol 16: 1984-1987, 1999

19. Rioux-Leclercq N, Epstein JI, Bansard JY, et al: Clinical significance of cell proliferation, microvessel density, and CD44 adhesion molecule expression in renal cell carcinoma. Hum Pathol 32: 1209-1215, 2001

20. Lucin K, Matusan K, Dordević G and Stipić D: Prognostic significance of CD44 molecule in renal cell carcinoma. Croat Med J 45: 703-708, 2004.

21. Gilcrease MZ, Guzman-Paz M, Niehans G, Cherwitz D, McCarthy JB and Albores-Saavedra J: Correlation of CD44S expression in renal clear cell carcinomas with subsequent tumor progression or recurrence. Cancer 86: 2320-2326, 1999.
22. Heider KH, Ratschek M, Zatloukal K and Adolf GR: Expression of CD44 isoforms in human renal cell carcinomas. Virchows Arch 428: 267-273, 1996

23. Matusan K, Dordevic G, Mozetic V and Lucin K: Expression of osteopontin and CD44 molecule in papillary renal cell tumors. Pathol Oncol Res 11: 108-113, 2005.

24. Lee SM, Lee KE, Chang HJ, et al: Prognostic significance of CD44s expression in biliary tract cancers. Ann Surg Oncol 15: 1155-1160, 2008

25. Takaishi S, Okumura T, Tu S, Wang SS, Shibata W, Vigneshwaran R, Gordon SA, Shimada Y and Wang TC: Identification of gastric cancer stem cells using the cell surface marker CD44. Stem Cells 27: 1006-1020, 2009.

26. Zeilstra J, Joosten SP, Dokter M, Verwiel E, Spaargaren M and Pals ST: Deletion of the WNT target and cancer stem cell marker $\mathrm{CD} 44$ in $\mathrm{Apc}\left(\mathrm{Min} /{ }^{+}\right)$mice attenuates intestinal tumorigenesis. Cancer Res 68: 3655-3661, 2008

27. Jin L, Hope KJ, Zhai Q, Smadja-Joffe F and Dick JE: Targeting of CD44 eradicates human acute myeloid leukemic stem cells. Nat Med 12: 1167-1174, 2006.

28. Krause DS, Lazarides K, von Andrian UH and van Etten RA: Requirement for CD44 in homing and engraftment of BCR-ABLexpressing leukemic stem cells. Nat Med 12: 1175-1180, 2006.

29. Huh JW, Kim HR, Kim YJ, Lee JH, Park YS, Cho SH and Joo JK: Expression of standard CD44 in human colorectal carcinoma: association with prognosis. Pathol Int 59: 241-246, 2009.

30. Terpe HJ, Störkel S, Zimmer U, Anquez V, Fischer C, Pantel K and Günthert U: Expression of CD44 isoforms in renal cell tumors. Positive correlation to tumor differentiation. Am J Pathol 148: 453-463, 1996.

31. Zolota V, Tsamandas AC, Melachrinou M, Batistatou A and Scopa C: Expression of CD44 protein in renal cell carcinomas: association with p53 expression. Urol Oncol 7: 13-17, 2002. 